\title{
An evaluation of Dehydration Assessment and Zinc Administration in Children with Acute Diarrhea in Hospitals
}

\author{
Septi Wardani ${ }^{1}$, Sri Hananto Ponco Nugroho ${ }^{2}$, Setiyo Budi Santoso ${ }^{3}$ \\ \{septiwardani@ummgl.ac.id ${ }^{1}$ \}
}

Department of Nursing, Universitas Muhammadiyah Magelang, Magelang, Indonesia ${ }^{1,2}$

Department of Pharmacist, Universitas Muhammadiyah Magelang, Magelang, Indonesia ${ }^{3}$

\begin{abstract}
Improper management of diarrhea, either at home or in hospital, is one of the main causes of death in children with diarrhea. The problems that arise in the management of diarrhea in children in the hospital are the unclear classification of degrees of dehydration, parents do not know the administration of zinc tablets and the unclear discharge planning. The purpose of this study was to investigate how the assessment of dehydration and zinc administration in children with acute diarrhea in hospital in Magelang, Indonesia. The method used is a case study. Subjects in this study were nurses who managed acute diarrhea. Data collection was carried out by means of observation, documentation and interviews. The results showed that the assessment of dehydration was not specific, the duration and dose of zinc had been given correctly but education on zik administration had not been carried out properly. In conclusion, we found several strengths and weaknesses in the assessment of dehydration and zinc administration in acute diarrhea children in hospital.
\end{abstract}

Keywords: Children, acute diarrhea, management, dehydration assessment, zink administrtation

\section{Introduction}

Diarrhea is still a major problem of child illness and death. To overcome this problem, the World Health Organization (WHO) has developed a framework for child health services in hospitals, one of which is the management of diarrhea for children, namely with five steps to complete diarrhea, which includes: (1). Giving orlait, (2). Giving zinc, (3). Selective antibiotics and antidiarrheals are not given, (4). Feeding and continuing with breastfeeding, (5). Providing advice to parents about when to bring their child back to the hospital [1]-[4].

The main cause of death among children under five in Indonesia is diarrhea, which is $16.7 \%$. This happens because the knowledge of health workers about the management of diarrhea is still low, as evidenced by the knowledge of officers about the history of diarrhea sufferers correctly by $43.7 \%$, knowing the determination of dehydration by $29.9 \%$, knowing the management of diarrhea without dehydration as much as $33.3 \%$, knowing the management of moderate or mild dehydrated diarrhea by $12.6 \%$ and knowing the management of severe dehydrated diarrhea by $14.9 \%$ [5],[6].

Assessment of the level of dehydration in children with diarrhea is very important because it is the basis for further management. Zinc is important because it can replace the natural zinc 
content lost in the body, can accelerate the healing of diarrhea, reduce the duration and severity of diarrhea and reduce the incidence of diarrhea for 2-3 months. In handling diarrhea, instructions are also given so that parents understand how to administer fluids and medicines at home and know the signs of when must to bring their child back to the hospital [5],[7],[8].

\section{Method}

The study design used a case study, to investigate how the assessment of diarrhea and zinc administration as management of acute diarrhea in children in the hospital. The place where the research was conducted at hospital in Magelang Indonesia. Collecting data from observations, interviews and progress note documents. Observations were made by looking at the actions of nurses in handling children with diarrhea. Interviews were conducted with nurses who provided direct management of children suffering from acute diarrhea, documents were carried out by looking at Nursing Care Standards and Standard Operating Procedures, as well as seeing records of child development. The tool used is a tool for assessing the quality of health services for sick children at the referral hospital. These three sources of evidence are used to investigated how the management of diarrhea in children in hospital. The analysis was carried out in 5 stages. The first stage is data reduction or entering data into a different list of the three sources of evidence. The second stage creates a category matrix and places the evidence into those categories. Category matrices are created by defining themes, sub-themes and categories. The third stage is to check the data that has been entered into the category. The fourth stage is to tabulate all categories of data sources, including interviews, documents and observations. The fifth step is to examine the complexity of tabulations and order them chronologically. The validity test was carried out by means of source triangulation. The source used is the child's parent

\section{Results and Discussion}

\subsection{Dehydration assessment}

The results of research on the quality of children's health services on dehydration assessment can be seen in Table 1.

Table 1. Average scoring for the quality of child health services (dehydration scoring)

\begin{tabular}{cc}
\hline Component & Average \\
\hline Dehidration scoring & 2 \\
\hline
\end{tabular}

The score obtained on the dehydration assessment is 2 , meaning that all patients have not been assessed for their level of dehydration correctly, even though there are incomplete standard operating procedures. This is not in accordance with WHO (2009), that the assessment of degree of dehydration should be carried out correctly in all diarrhea patients based on the national recommended classification and in accordance with the Handbook for Child Health Services in First Level Referral Hospitals in Districts / City [1]. From the results of interview, observation and document data sources, the categories for the results of the degree of dehydration assessment were obtained, as shown in the figure 1 below. 


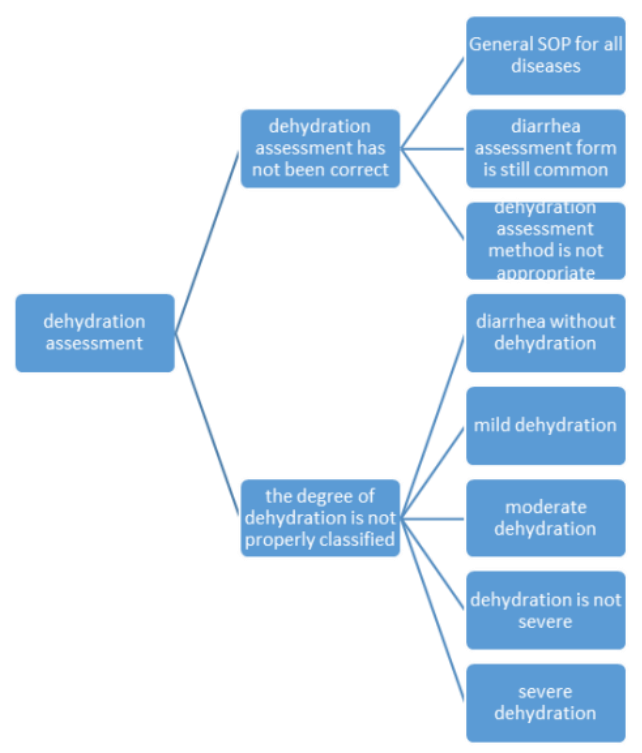

Fig. 1. The categories of dehydration assessment

From the picture above shows that the diarrhea assessment has not been carried out correctly, it is proven by the existence of: The available SOP is still general, not specific, as the informant stated:

"'SOP in general, yes .. so the handling of all patients in general types of diseases".

In the assessment of diarrhea, the form used was still general, the informant's statement which proved that:

"The nursing assessment form is not specific to dehydration but in general".

The dehydration assessment carried out is not appropriate, it was proven by the informant's statement:

"Check head to toe, under 2 years whether the crown is for example sunken or not .. crying can still come out tears no .. skin turgor can quickly return in 2 seconds or not .. lip mucosa ... weight".

Diarrhea assessments that have been carried out in the hospital are still in general, not specifically diarrhea assessments. This is not in accordance with the guidelines for children's health services in hospitals, that in children with diarrhea, anamnesis should be carried out regarding the history of feeding, the characteristics of diarrhea, including frequency of defecation, duration of diarrhea, blood in the stool and asked if the child vomits. In addition, they also asked about the existence of an extraordinary event in the child's residence, previous antibiotic treatment and checked for symptoms of invagination. Assessment of diarrhea is very important in the next treatment. By carrying out the assessment properly and correctly, it will be known what the clinical form of children's diarrhea will be. With the correct assessment, it will be known whether the child has acute diarrhea, cholera, dysentery, persistent diarrhea, antibiotic-related diarrhea or invagination [1].

The hospital classified the degree of dehydration into diarrhea without dehydration, diarrhea with mild dehydration, moderate dehydration, not severe dehydration and severe dehydration. This is not in accordance with WHO, which states that diarrhea is classified into 3 
levels of dehydration, namely without dehydration, mild / moderate dehydration and severe dehydration. The results showed that health workers classified the degree of dehydration by assessing the eyes, crying, tears, consciousness, urination, turgor and lip mucosa. This is not in accordance with WHO recommendations, that in assessing the degree of dehydration only uses 4 things, namely general condition, eyes, willingness to drink and skin turgor. It is said to be severely dehydrated if the child has two or more signs of lethargy, sunken eyes, cannot drink and the turgor skin back very slowly. Meanwhile, a child is categorized as mild / moderate dehydration if the child shows two or more signs of fussiness or restlessness, sunken eyes, drinks greedily and the turgor is slowly. For the categorization of diarrhea without dehydration, if the child has not signs to be classified as mild moderate or severe dehydration [1], [9].

\subsection{Zinc administration}

The results of the quality of children's health services on zinc administration are illustrated in Table 2.

Table 2. Average scoring for quality of child health services (zink administration)

\begin{tabular}{cc}
\hline Component & Average \\
\hline Zinc administration & 3,385 \\
\hline
\end{tabular}

Of the above components, the mean score was 3,385. In the explanation of the score, there was no score of 3.1 and so on. Because of this, the score of this component is rounded to a score of 3. This mean score means that there is zinc administration in children with diarrhea but it is not accurate, even though the standard operating procedures are complete

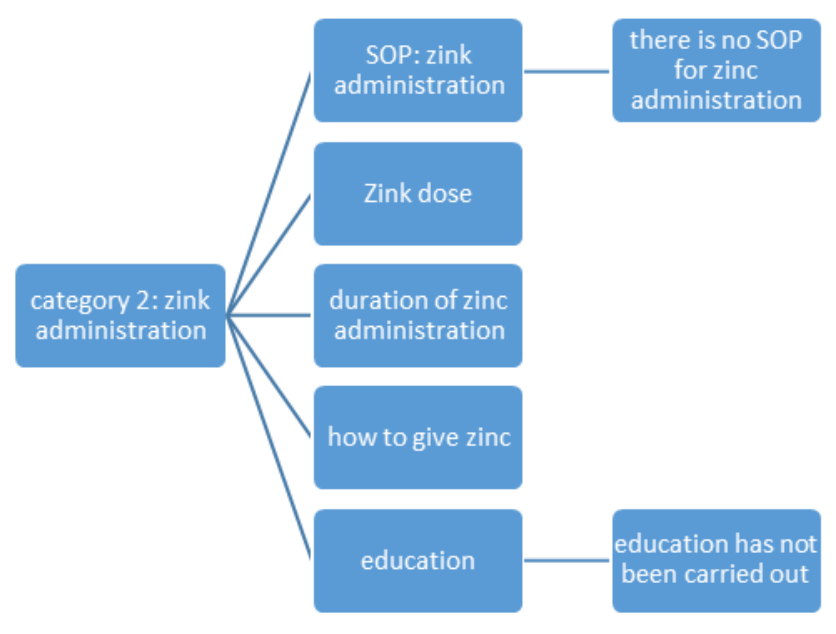

Fig. 2. Administration of zinc

From the picture above shows some of the findings in zinc administration. The findings were that there was no standard operational of procedure for zinc administration, the dose of zinc had been given correctly, the duration of administration of zinc was 10 days, if the children vomiting, zink then it was repeated after 10 minutes, and the education was not done properly. 
The absence of standard operating procedures in the administration of zinc was evidenced by the informant's statement,

"Not yet SOP, ma'am.." (I1).

Furthermore, officers already know the correct dose of zinc in children, namely given 10 mg to children aged less than 6 months and $20 \mathrm{mg}$ to children aged more than 6 months. This is supported by the informant's statement, namely

"The dose of zinc for under 6 months is $10 \mathrm{mg} /$ day if over 6 months we use $20 \mathrm{mg} /$ day" (I2).

The officers also knew how long it took to give zinc correctly, which was supported by the informant's statement that

"Don't stop drinking, it must be 10 days, so that diarrhea doesn't happen again"(I3).

The next result is that when the child vomits zinc, the zinc will be repeated after 10 minutes. This was supported by the informant's statement

"if the patient vomits, then take a 10 minute pause, then give it again" (I4).

The next result is that education in zinc administration has not been carried out properly, especially in the explanation of the length of time giving zinc to parents. This was evidenced by the informant's statement:

"how much yes .. maybe until it runs out, bro.." (Ip1).

The absence of SOP in the hospitals in administering zinc is not in accordance with WHO (2009), which states that there must be policies and procedures for giving zinc in the handling of children with diarrhea. WORLD Health Organization states that what is meant by complete SPO is the SOP for zinc administration as early as possible with the right dose according to the Handbook for Child Health Services Guidelines for First Level Referral Hospitals in districts / cities. The absence of SPO for zinc administration is also not in accordance with the Decree of the Minister of Health of the Republic of Indonesia No 496 / Menkes / SK / IV / 2005, regarding guidelines for medical audits in hospitals. The ministerial decree states that hospitals are required to provide medical services in accordance with established professional standards and standard operating procedures. The results of zinc administration at hospitals showed that the dose of zinc given was $10 \mathrm{mg}$ for children aged less than 6 months and $20 \mathrm{mg}$ for children older than 12 months. This is in accordance with the Ministry of Health which states that zinc is given to children aged 2 months and over for 10 days with a dose: children aged less than 6 months are given $10 \mathrm{mg}$ (1/2 tablet) per day and children over age. from 6 months given $20 \mathrm{mg}$ ( 1 tablet) per day. Zinc is a micronutrient that is very important for the body. In the condition of diarrhea, the child will lose zinc in his body and there will be an increase in the excretion of the enzyme INOS (Inducible Nitric Oxide Synthase), which will result in intestinal epithelial hyperexpression. By administering zinc, it can inhibit the increase in the INOS enzyme and will support the epithelialization of the intestinal wall which is damaged during diarrhea. In addition, zinc can replace the lost natural zinc content in the body and can accelerate the healing of diarrhea [5], [10], [11].

The results showed that the officers already knew how long they were giving zinc properly. Administration of zinc for 10 days and given in the correct dosage. with the supplementation of $20 \mathrm{mg}$ per day until diarrhea stops can reduce the duration and severity of diarrhea in children in developing countries. Then with the continued administration of zinc for 10 days can reduce the incidence of diarrhea for 2-3 months. This will help reduce child mortality from diarrhea.

According to Lazzerini and Ronfani, zinc supplementation can reduce the duration and severity of diarrhea in children suffering from diarrhea. In hospitals, zinc is given directly to the child according to the dose in the form of syrup and if after giving the child vomits, it is repeated after 10-15 minutes [12]. This is in accordance with the Ministry of Health, which states that 
the method of giving zinc is by dissolving zinc in one tablespoon of boiled water or breast milk, or it can be taken directly by children according to the dose if it is in the form of suspension. Furthermore, if the child vomits after giving zinc, then the zinc administration can be repeated again after 10 minutes. The results showed that the officers already knew the dose and duration of zinc administration, but the family did not know how long it took for their children to give zinc. This shows that the officers have not provided clear education to the family regarding the duration of zinc administration. This is not in accordance with WHO, which provides guidelines that in administering zinc, officers must teach mothers or their families about zinc doses, how to give zinc and provide explanations and remind mothers to give zinc to their children for 10 days. full. According to Mazumder, education on giving zinc to children for 10 days is very important to be given to parents because it will reduce the duration of diarrhea and prevent diarrhea in the next 3-4 months. Zinc should be given to children with diarrhea for 10 full days because it provides many benefits for children [13], [14]. According to Lukaclk, et al, giving zinc supplements in acute diarrhea can reduce the duration of diarrhea and also reduce the severity of diarrhea. The duration of diarrhea can be reduced because the administration of zinc will increase the absorption of fluids and electrolytes by the intestines and the intestinal epithelium which is damaged during diarrhea will regenerate more quickly with administration. In addition, zinc can increase the clearance of pathogens in the intestine and can strengthen the body's immune response [4], [15], [16].

\section{Conclusion}

Was found several strengths and weaknesses in the assessment of dehydration and zinc administration in children with acute diarrhea in hospital.

\section{Acknowledgement}

This research was funded by the Directorate of Research and Community Service (DRPM). For that we would like to thank the DRPM for providing opportunities in research and funding support. We also express our gratitude to the Institute for Research and Community Service (LPPM) Muhammadiyah Magelang University for providing opportunities and guidance in the preparation of manuscripts and publication of this scientific paper. In addition, we are grateful to the hospital in Magelang and all respondents who deigned to participate in the research process.

\section{References}

[1] I. WHO, Depkes, Buku Saku Pelayanan Kesehatan Anak Di Rumah Sakit Pedoman Bagi Rumah Sakit Rujukan Tingkat Pertama Di Kabupaten/ Kota. WHO, 2009.

[2] N. A. Sidik et al., "Assessment of the quality of hospital care for children in Indonesia," Trop. Med. Int. Heal., vol. 18, no. 4, pp. 407-415, 2013.

[3] A. Diallo, X. Cong, W. Henderson, and J. MsGrath, "Management of childhood diarrhea by healthcare professionals in low income countries: An integrative review," Int. Jiurnal Nurs. Stud., vol. 66, pp. 82-92, 2017. 
[4] G. Alfredo, "Universal Recommendations for the Management of Acute Diarrhea in Nonmalnourished Children,” J. Pediatr. Gastroenterol. Nutr., vol. 67, no. 5, pp. 586-593, 2018.

[5] K. kesehatan RI, "Situasi Diare Di Indonesia," Kementrian Kesehatan RI, 2011.

[6] RISKESDAS, "Hasil Utama Riskesdas 2018,” Jakarta: Kemenkes RI, 2018.

[7] J. Chen et al., "Chinese clinical practice guidelines for acute infectious diarrhea in children," World J. Pediatr., no. 0123456789, 2018.

[8] H. R. Feldmann, D. R. Williams, J. D. Champagne, T. W. Lehenbauer, and S. S. A. Id, "Effectiveness of zinc supplementation on diarrhea and average daily gain in pre- weaned dairy calves : A doubleblind, block- randomized , placebo-controlled clinical trial," pp. 1-22, 2019.

[9] D. P. Falszewska A, Szajewska H, "Clinical Scales for Assessment of Dehydration in Children with Diarrhea," Indian Pediatr., vol. 55, pp. 513-518, 2018.

[10] G. Laghari, Z. Hussai, and H. Sahzad, "Effect of Zinc Supplementation on the Frequency and Consistency of Stool in Children with Acute Diarrhea," PMC, vol. 11, no. 3, 2019.

[11] W. B. Putri, S. A. Akhmad, and . Sufi Desrini, "The role of zinc supplementation for diarrhoea in children: a critical review," Bangladesh J. Med. Sci., vol. 18, no. 2, 2019.

[12] Lazzerini M. \& Ronfani M, "Oral zinc for treating diarrhoea in children in the developing world," Cochrane Database Syst. Rev., vol. CD005436., no. 3, 2008.

[13] Mazdumer, "Effectiveness of zinc supplementation plus oral rehydration salts for diarrhoea in infants aged less than 6 months in Haryana state, India," Bull World Heal. Organ, vol. 88, no. 10.2471, pp. 754-760, 2010.

[14] A. S. Yazar, S. Guven, and E. C. Dinleyici, "Effects of zinc or synbiotic on the duration of diarrhea in children with acute infectious diarrhea," vol. 2016, no. November, 2016.

[15] A. Lukacik, Thomas, "A Meta-analysis of the Effects of Oral Zinc in the Treatment of Acute and Persistent Diarrhea," Pediatrics, vol. 121, no. 2, 2014.

[16] L. Rerksuppaphol and S. Rerksuppaphol, "Efficacy of zinc supplementation in the management of acute diarrhoea: a randomised controlled trial," Publ. Cover Paediatr. Int. Child Heal., vol. 40, no. 2, 2020 